\title{
Analysis of the applicative potential of pigments extracted from bacterial isolates of mangrove soil as topical UV protectants
}

\author{
Jyoti M Patki ${ }^{\circledR *}$, Suvidha Singh ${ }^{1}$, Sunita Singh ${ }^{1}$, \\ Naveen Padmadas ${ }^{1}$, Debjani Dasgupta ${ }^{1}$
}

\author{
${ }^{1}$ School of Biotechnology and Bioinformatics, D.Y. Patil Deemed to be University, \\ Navi Mumbai CBD Belapur, Navi Mumbai, Maharashtra, India
}

\begin{abstract}
Antioxidant, antibacterial and UV protective activities of two pigments extracted from mangrove soil isolates were analysed for their applications as ingredients in sunscreen formulations. Through biochemical characterization, the isolates were tentatively identified as belonging to the Flavobacterium sp. and Brevibacterium sp. UV visible spectral characterization of the pigments indicated presence of carotenoids. The orange pigment exhibited Sun Protection factor (SPF) value of 5.3 while the yellow pigment SPF was found to be 2.60. Both isolates as well as their pigments revealed tolerance to UVA-B radiation and to UVC radiation, to comparatively lesser extent. Yellow pigment exhibited good antibacterial activity with maximum effect on Escherichia coli, Corynebacterium diptheriae and Staphylococcus aureus. Both pigments were capable of reducing DPPH radical with $\%$ DPPH inhibition of $52.36 \%$ (orange pigment) and $40.1 \%$ (yellow pigment). These findings suggest that both pigments show promise of making excellent natural components of cosmetic formulations, especially sunscreens.
\end{abstract}

Keywords: Carotenoids. Sunscreen. UV protection. Antibacterial. Antioxidant.

\section{INTRODUCTION}

The size of India's cosmetic market is predicted to reach $\$ 20$ billion by 2025 and India will be the largest consumer with $5 \%$ market share in the global beauty sector (Anand, 2017). Pigments and colours go hand in hand with cosmetics and personal care products. From lip colours, nail enamels, hair dyes to facial creams, sunscreens, soaps and face washes, pigments are used in all personal care products. Pigments with additional properties are required in sunscreen formulations. For example, titanium dioxide or zinc oxide is used for manufacturing white colour cosmetic products and are also key ingredients in most of the sunscreen formulations due to their UV light filtering properties.

*Correspondence: J. M. Patki. The School of Biotechnology and Bioinformatics. D.Y. Patil Deemed to be University. Navi Mumbai, Sector-15, Plot-50, CBD Belapur. Navi Mumbai- 400614 Maharashtra, India. Phone: 91-22-27563600. Fax: 91-22-27567976. E-mail: jyoti.tope@ dypatil.edu; orcid.org/0000-0003-1271-3799
While protection of human skin from UV radiation is the primary requisite of sunscreen ingredients, adverse effects like contact sensitivity and oestrogenecity (Ishihashi, et al., 2003) show that there is a clear need for seeking safer alternatives. While bacterial pigments serve various purposes in their producers, protection from harmful UV radiation is an important function. Habitats exposed to high solar radiations including deserts, polar regions and intertidal marine zones exhibit a vast micro-biota of the pigmented kind that can render protection through absorption or screening of UV radiations (Siezen, 2011). Bacteria produce a wide range of pigments such as carotenoids, melanin, violacein, prodigiosin, monascin, pyocyanin, actinorhodin, and zeaxanthin (Narsing, Xiao, Li, 2017).

Among the microbial pigments, carotenoids are the most widely observed and studied. Given the antimicrobial, antioxidant and UV protective properties often associated with carotenoids, their application as sunscreen components is a promising one (Samyukta, 
Mahajan, 2016). In the present study, we explore the applicative potential of two pigments extracted from bacteria isolated from mangrove soil. The main objectives of the study were to isolate and characterize pigmented bacteria from mangrove soil, to extract and characterize the pigments and to analyse their applicative potential with respect to use in skin care formulations. The fact that the pigmented isolates were extracted from mangrove soil give more reason to believe that the pigments analysed in the present study are likely to have the desired characteristics.

The pigments were tested for UV protection, antioxidant and antibacterial properties. The combined presence of these properties suggest better applicative potential in cosmetic and health care with greater efficacy and added value while diminishing the risk of toxicity and environmental hazard.

\section{MATERIAL AND METHODS}

\section{Bacterial strains}

The test bacterial strains used for antibacterial analysis of pigments were in-house cultures originally obtained from Microbial Culture Collection (MCC), Pune (now named as the National Centre for Microbial Resource, NCMR) and stored at $-80{ }^{\circ} \mathrm{C}$ in BHI (Brain Heart Infusion) broth supplemented with $10 \%$ glycerol.

\section{Reagents}

All chemicals were analytical grade or ultra-pure grade. Chloroform, methanol, ethanol, 2,2-diphenyl-1picrylhydrazyl (DPPH) reagent, Ascorbic acid, sodium acetate, $\mathrm{H}_{2} \mathrm{SO}_{4}$ were purchased from SRL Pvt. Ltd. Penicillin, nutrient agar and Muller Hinton agar were purchased from HiMedia.

\section{Study area and Sampling}

The rhizosphere soil was collected from the most dominant mangrove species Avicennia marina and Acanthis illcipholivs distributed in the Navi Mumbai proposed International airport location $\left(18^{\circ} 59^{\prime} 40^{\prime \prime} \mathrm{N} 073^{\circ} 04^{\prime} 13^{\prime \prime} \mathrm{E}\right)$. Five samples were collected from 5 spots evenly separated from each other over a 100 -meter square area and the samples were pooled. Five such 100-meter square areas were identified generally with interior locations accessible only by water route.
Rhizosphere soil was collected at a depth of $20 \mathrm{~cm}$ from the area around the roots of the mangrove plants. The samples were placed in sterile polypropylene containers and maintained at $4{ }^{\circ} \mathrm{C}$ before being transported to the laboratory (Wu et al., 2016). The soil sample was collected during dry season, that is, pre-monsoon.

\section{Isolation and characterization of soil bacteria}

One gram of soil was dissolved in $10 \mathrm{~mL}$ of sterile saline in a $50 \mathrm{~mL}$ Erlenmeyer flask and mixed by vortexing. The samples were serially diluted up to $10^{-}$ 8. $100 \mu \mathrm{L}$ of each dilution was spread on Nutrient agar plates and incubated at $37^{\circ} \mathrm{C}$ for $24-72 \mathrm{~h}$. Morphologically distinct colonies with characteristic pigments were picked and streaked on Nutrient agar plates to obtain pure culture. Following study of colony characteristics and biochemical analysis, the isolates were identified using Bergey's manual of Determinative Bacteriology (Holt JG et al., 1994)

\section{Pigment extraction}

The isolates were inoculated in $20 \mathrm{~mL}$ nutrient broth (NB) in $100 \mathrm{~mL}$ Erlenmeyer flask at $37^{\circ} \mathrm{C}$ on a shaker set at $200 \mathrm{rpm}$. The OD was monitored from time to time at $600 \mathrm{~nm} .2 \mathrm{~mL}$ of the culture at OD of 1.0 was inoculated in $100 \mathrm{~mL}$ of the fresh NB medium in 500 $\mathrm{mL}$ Erlenmeyer flask and incubated at $37^{\circ} \mathrm{C}$ at $200 \mathrm{rpm}$ for $72 \mathrm{~h}$.

The culture broth was centrifuged at $9015.55 \times \mathrm{g}$ for 10 min to harvest the bacteria. The resulting pellet was washed once with sterile distilled water followed by centrifugation at $4006.91 \mathrm{xg}$ for $5 \mathrm{~min}$ to recover the cells by decanting the supernatant. The isolates $\mathrm{P} 2$ and $\mathrm{P} 4$ gave colourless supernatant and pellet. Hence, the further extraction was carried out only for $\mathrm{P} 1$ and $\mathrm{P} 3$ isolates. The recovered cells were extracted using $10 \mathrm{~mL}$ of $95 \%$ methanol. The mixture of cells and solvent was sonicated (100 watts; $33 \mathrm{kHz})$ (Dakshin Ultra-sonicator) for $20 \mathrm{~min}$. The pigment was then separated from the cells by centrifugation at 6260.8 $\times \mathrm{g}$ for $5 \mathrm{~min}$ at $4{ }^{\circ} \mathrm{C}$. This process was repeated until the cells were completely bleached. The resulting pigment was concentrated using rotary evaporator under reduced pressure (Superfit TM Rotary Vacuum Evaporator) at $50^{\circ} \mathrm{C}$ and dried for three days at $40{ }^{\circ} \mathrm{C}$ to powder. All steps were carried out at low light conditions to avoid pigment degradation. The dried pigment was collected in screw capped bottles and stored at $-20{ }^{\circ} \mathrm{C}$. The methanol extracts were used for spectrophotometric analysis (ÓrdenesAenishanslins, et al., 2016). 


\section{Determination of dry cell weight}

About $10 \mathrm{~mL}$ of isolate broth culture was added in triplicate to pre-weighed Eppendorf tubes and centrifuged for $20 \mathrm{~min}$ at $4006.91 \times \mathrm{g}$. Cell pellets were washed with sterile distilled water and dried until constant mass at $105^{\circ} \mathrm{C}$ for $24 \mathrm{~h}$. The final weight was measured and the dry cell weight (DCW) was calculated according to the formula (Jalal et al., 2014)

\section{Pigment analysis}

\section{Spectrophotometric analysis and estimation of Total carotenoid (TC) content}

The $\lambda \max$ of the methanolic pigment extract from two isolates was determined using UV-Vis spectrophotometer (UV-Vis Double Beam Chemito Spectrascan UV 2600) between 400 and $550 \mathrm{~nm}$ (Venil et al., 2014).

For the orange pigment, the total carotenoid content was measured spectrophotometrically by taking the absorbance readings at $448 \mathrm{~nm}$ (beta carotene). For the yellow pigment, absorbance was taken at $450 \mathrm{~nm}$ (zeaxanthin). The total carotenoid content was calculated using the formula

$\% \mathrm{CV}=\frac{(\mathrm{CFU} / \mathrm{mL} \text { of } \mathrm{UV} \text { treated suspensions }) \times 100}{\mathrm{CFU} / \mathrm{mL} \text { of untreated suspensions }}$

Where,

$\mathrm{A}=$ Absorbance at $448 \mathrm{~nm}$ (orange); $450 \mathrm{~nm}$ (yellow)

$\mathrm{V}=$ Volume of the extract

$10^{4}=$ Correction factor to obtain concentration in $\mu \mathrm{g} / \mathrm{mL}$ (Rivera, Canela, 2012).

$\mathrm{E} 1 \%=$ Coefficient of absorbance, for orange pigment equivalent to beta carotene (2550) using methanol as the solvent; for yellow pigment equivalent to zeaxanthin (2540) with methanol as a solvent.

\section{Qualitative determination of Carotenoids}

Exactly $1.0 \mathrm{~g}$ of dry weight of harvested cells was extracted with $10 \mathrm{~mL}$ of chloroform in a test tube with vigorous shaking. The resulting mixture was filtered and $85 \%$ sulphuric acid was added. A blue colour at the interface showed the presence of carotenoids (Ajayi, Ajibade, Oderinde, 2011).

\section{Ultraviolet resistance}

In vitro measurement of SPF of the extracted pigments

A quantity of $1.0 \mathrm{~g}$ of extracted pigment was taken in a $100 \mathrm{~mL}$ volumetric flask and diluted with $75 \mathrm{~mL}$ of ethanol. The contents were sonicated for $10 \mathrm{~min}$ and volume made up to $100 \mathrm{~mL}$ with ethanol. The solution was filtered through Whatman No. 1 filter paper and the filtrate was collected by rejecting the first few $\mathrm{mL}$ of the same. Exactly $5 \mathrm{~mL}$ of the filtrate was diluted further with ethanol in a $50 \mathrm{~mL}$ volumetric flask and $5 \mathrm{~mL}$ of this was again diluted with ethanol in a $25 \mathrm{~mL}$ volumetric flask. The absorption spectra of the pigment solutions were obtained between 290 to $320 \mathrm{~nm}$ at $5 \mathrm{~nm}$ intervals and three observations were made at each point. (Dutra, et al., 2004) The in vitro SPF number was determined by the application of Mansur equation (Mansur et al., 1986)

$S P F_{\text {Spectrophotometric }}=C F \times \sum_{290}^{320} \mathrm{EE}(\lambda) \times \mathrm{I}(\lambda) \times \operatorname{Abs}(\lambda)$

Where: EE(l) - erythemal effect spectrum, I(l) - solar intensity spectrum, Abs(l) - absorbance of sunscreen product, $\mathrm{CF}$ - correction factor $(=10)$. The values of (EE x I) are constants and were obtained from literature (TABLE I) (Sayre et al. 1979).

TABLE I-Normalized product function used in the calculation of SPF (Sayre, et al., 1979)

\begin{tabular}{cc}
\hline Wavelength (nm) & EE×I (Normalized) \\
\hline 290 & 0.015 \\
\hline 295 & 0.0817 \\
\hline 300 & 0.2874 \\
\hline 305 & 0.3278 \\
\hline 310 & 0.1864 \\
\hline 315 & 0.0839 \\
\hline 320 & 0.018 \\
\hline Total & 1 \\
\hline
\end{tabular}

EE-erythemal effect spectrum

I- solar intensity spectrum 


\section{UV protection}

The UV resistance of $\mathrm{P} 1$ and $\mathrm{P} 3$ bacterial isolates were determined following the procedure described in literature with some modifications. UV light sensitive strain $E$. coli was used as an indicator strain. All three bacterial cultures were grown to exponential phase in NB. After diluting with PBS, the suspensions were placed in glass tubes and subjected to UV irradiation in a laminar flow cabin. A UV light source of $254 \mathrm{~nm}$ was used for UV-C radiation and a 400W lamp (320-400 nm) was used for UVA-B radiation. The exposure time was up to $60 \mathrm{~min}$. Following the exposure, the suspensions were plated on NA medium and incubated for 3 days at $37^{\circ} \mathrm{C}$. The number of colony-forming units (CFU) were recorded. Isolates not exposed to $\mathrm{UV}$ radiation (untreated) were used as controls (Mohammedi, Burbank, Roper, 2012). The resistance of the isolates to UV radiation was assessed by determining percentage Cell Viability $(\% \mathrm{CV})$ using the formula:

$$
\% \mathrm{CV}=\frac{(\mathrm{CFU} / \mathrm{mL} \text { of } \mathrm{UV} \text { treated suspensions }) \times 100}{\mathrm{CFU} / \mathrm{mL} \text { of untreated suspensions }}
$$

In another experimental set up, methanol extracts of both pigments were tested for their ability to offer physical protection from UV radiation to UV sensitive E. coli strains (Mohana, Thippeswamy, Abhishek, 2013). Dilutions of UV sensitive E. coli culture were placed in sterile watch glass covered with cling film. Then $2 \mathrm{~mL}$ of $95 \%$ aqueous methanol solution of the pigment extracts was placed over the cultures in the depression of the cling film. The cultures were thus exposed to UV-C and UVA-B radiation as described before. The dilutions were removed at $15 \mathrm{~min}$ intervals and plated on NA medium. The $\% \mathrm{CV}$ was determined as described before.

\section{Photo-stability of the pigments}

To determine the photo-stability of bacterial pigments, samples were normalized to 1.0 arbitrary unit of absorbance by dilution according to their maximum absorbance peak (450 and $478 \mathrm{~nm}$ for yellow and red pigment, respectively). Then, pigments were exposed to light $(\sim 70 \mathrm{~mW} \cdot \mathrm{cm}-2)$ and the decay of maximum absorbance peak of each sample was measured every $10 \mathrm{~min}$ during $1 \mathrm{~h}$. To avoid solvent evaporation, the temperature of the experiment was controlled $\left(16^{\circ} \mathrm{C}\right)$. The experiment was performed in triplicate and a dark condition was used as control (Órdenes-Aenishanslins, et al., 2016).

\section{Antibacterial properties}

Antibacterial activities of the Yellow and Orange pigments were assayed against laboratory strains of Gram-negative bacteria Escherichia coli, Klebsiella pneumonie and Pseudomonas aeruginosa and Grampositive bacteria Staphylococcus aureus, Bacillus subtilis, Sarcina lutea and Corynebacterium diphtheriae. Overnight, broth cultures of the test bacteria were inoculated $(100 \mu \mathrm{L})$ on Muller Hinton Agar (MHA) by spread plate.

The disc diffusion method was employed to evaluate the activity of the extracted pigments. Sterile filter paper discs (6 $\mathrm{mm}$ in diameter) were soaked in pigments $(0.5$ $5 \mathrm{mg} / \mathrm{mL}$ ), placed onto the pre-inoculated MHA plates and incubated at $37^{\circ} \mathrm{C}$ for $24 \mathrm{~h}$. The zone of inhibition (ZOI) diameters were measured in millimeters $(\mathrm{mm})$. Penicillin discs were placed as comparative standards (Rostami, Hamedi, Yolmeh, 2016).

\section{Antioxidant properties}

\subsection{2,2-Diphenyl-1-picrylhydrazil (DPPH) Assay}

Radical scavenging activity of the extracted pigments was investigated by the DPPH assay. The method is based on the reduction of alcoholic DPPH solution in the presence of hydrogen donating antioxidant resulting in formation of non-radical DPPH-H. In $0.5 \mathrm{mM}$ of DPPH methanolic solution $(1.5 \mathrm{~mL}), 1.5 \mathrm{~mL}$ of pigment extracts (100-500 $\mu \mathrm{g} / \mathrm{mL})$ were added along with $2 \mathrm{~mL}$ of $0.1 \mathrm{M}$ acetate buffer ( $\mathrm{pH}$ 5.5). Ascorbic acid was used as a standard in the same range of concentrations. After incubating for $30 \mathrm{~min}$ at $37^{\circ} \mathrm{C}$, absorbance was measured at $517 \mathrm{~nm}$ using a UV spectrophotometer. Absorbance of DPPH with no addition of standard or pigment extract was considered as control. Lower absorbance compared to control indicates radical scavenging activity which can be compared with the standard antioxidant of known potency. The percentage scavenging activity was calculated using the formula;

$\%$ Scavenging $=\frac{\left(A_{c}-A_{s}\right)}{\left(A_{c} \times 100\right)}$ 
Where, Ac $=$ control absorbance (without sample). As $=$ sample absorbance (pigment extracts or ascorbic acid) (Tarangini, Mishra, 2014).

\section{Statistical analysis}

All experiments and measurements (photostability, UV radiation treatments, antibacterial activity and antioxidant activity) were carried out in triplicate. Arithmetic mean, standard deviation and standard error were calculated. Mean values were plotted in bar graph with error bars showing standard error. Differences between group means were tested for statistical significance by Student's $t$-test. Accordingly, the tolerance exerted by both pigmented isolates ( $\mathrm{P} 1$ and P3) to UV radiation was compared with that of E. coli strain. The protection provided by both pigment extracts against UV radiation was compared with that provided by methanol and direct exposure. $P$ values $\leq 0.01$ were considered to be significant. All statistical analyses were performed using Microsoft Excel.

\section{RESULTS AND DISCUSSION}

\section{Isolation and Characterization of Soil Bacteria}

Four pigmented isolates were obtained from the soil samples and were designated as P1, P2, P3 and P4 that produced yellow and orange coloured colonies. Based on the colony characteristics, cell morphology and biochemical properties shown in Table II, the isolates were tentatively identified as belonging to the Flavobacterium sp. (P1) and Brevibacterium sp. (P3). Since P2 and P4 did not yield pigments in subsequent extraction only $\mathrm{P} 1$ and P3 were selected for further scrutiny.

Pigment producing bacteria shows ubiquitous distribution and have been reported to be present in diverse ecological niches. Several pigmented bacteria have been reported to be a part of the mangrove microbial community. Diazotropic red pigmented vibrios were isolated from mangrove rhizosheres (Rameshkumar, Nair, 2009). The orange pigmented bacterial isolate, in the present study, was identified as belonging to the Brevibacterium species. Brevibacterium sp. was found to be a predominant bacterial genus amongst other bacteria isolated from mangrove soil in Karandu Tamil Nadu during summer (Saseeswari, Kanimozhi, Panneerselvam, 2016). Gavrish et al. in 2004, identified three novel species of Brevibacteria all known to produce orange pigment.

The yellow pigment isolate of the present study was classified to the Flavobacterium genus. Flavobaterium genus has over hundred different strains with exceptional environmental niche heterogeneity showing distribution in the soil and aquatic habitats. These are gram negative aerobic motile rods and produce yellow colonies.

TABLE II - Morphological and Biochemical characterization of isolates

$\begin{array}{lll}\text { Characteristic } & \text { P1 } & \text { P3 }\end{array}$

\section{Morphological characteristics}

\begin{tabular}{lcl}
\hline Gram staining & Gram Negative & Gram Positive \\
\hline Cell shape & Rods & Irregular rods
\end{tabular}

Colony morphology

Optimum growth

temperature (C)

\author{
Circular. Flat, entire margin, \\ smooth and yellow
}

Circular. Flat, entire margin, smooth and slight orange

Optimum $\mathrm{pH}$

$37^{\circ} \mathrm{C}$

$37^{\circ} \mathrm{C}$

6-10 optimum 8

6-10 optimum 8

Fluorescence under UV light 
TABLE II - Morphological and Biochemical characterization of isolates

\begin{tabular}{|c|c|c|}
\hline Characteristic & P1 & P3 \\
\hline \multicolumn{3}{|c|}{ Biochemical characteristics } \\
\hline Catalase & + & + \\
\hline Indole & + & - \\
\hline Methyl Red & + & - \\
\hline Urease & - & + \\
\hline Voges proskauer & - & - \\
\hline Starch hydrolysis & - & - \\
\hline Oxidase & + & - \\
\hline $\mathrm{H} 2 \mathrm{~S}$ & + & - \\
\hline
\end{tabular}

\section{Pigment extraction and characterization}

The pigments were extracted in $95 \%$ aqueous methanol. Carotenoids are hydrophobic pigments almost insoluble in water even at high temperatures but soluble in organic solvents.

Both pigments exhibited an absorption spectrum quite characteristic of carotenoids between 400-550 $\mathrm{nm}$. (Figure 1). The primary diagnostic tool for the identification of carotenoids is to study the spectrum of the organic solvent extract. The absorption spectra of both the pigment extracts (Figure 1) suggest the presence of carotenoids. Chavez-Parga et al. in 2012, reported the production of zeaxanthin by Flavobacterium sp. Brevibacterium sp. strain KY4313 has been reported to produce canthaxanthin and small amount of echinenone and beta carotene (Joshi, et al., 2003). The pigment extracts showed positive reaction in the chemical identification of carotenoids test supporting the spectrophotometric results.

\section{Total carotenoid content (TCC)}

The total carotenoid content of the orange pigment was slightly higher than the yellow pigment (Table III). Different methods have been proposed for the measurement of total carotenoid content of the extracted pigments and these methods are based on the application of the beer lambert's law for multicomponent systems. The total carotenoid content obtained in this study for both pigments was comparable with observations made by other investigators in similar pigment extraction studies. Dufosse et al. in 2001, reported a carotenoid yield between 200-1000 $\mu \mathrm{g} / \mathrm{g}$ in methanol pigment extracts of Brevibacterium linens. TCC ranged between 0.7-0.8 mg/g. Tarangini, Mishra, in 2014, demonstrated melanin production on $15 \%$ increase pigment yield by optimization with Taguchi approach $(0.655 \mathrm{mg} /$ $\mathrm{mL}$ ). Employment of optimization strategies will help improve the yield of carotenoids from the isolates. 


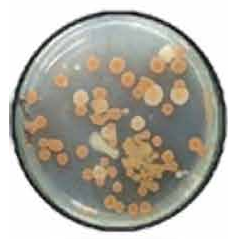

A

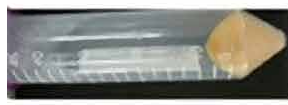

C

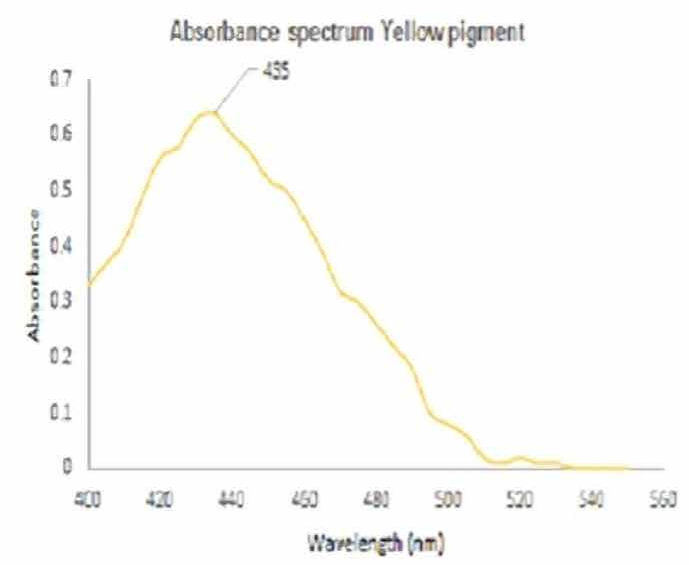

E
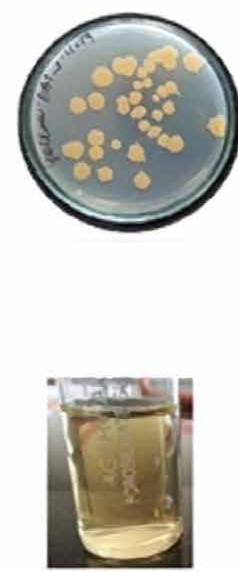

B
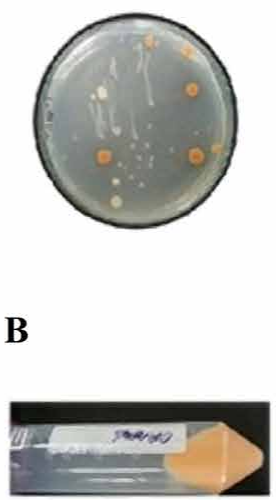

D

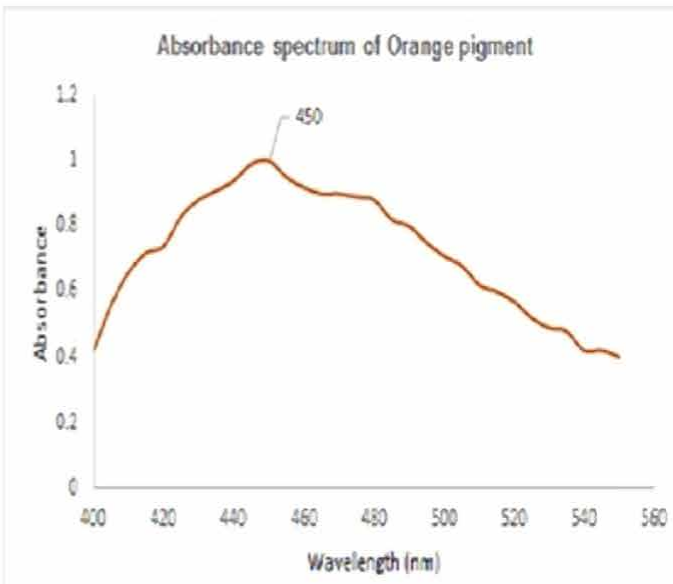

F

FIGURE 1 - Isolate plates P1 (A) and P3 (B); pellets and methanol extracts of the carotenoid pigments of P1 (C) and P3 (D); absorption spectra of pigments extracted from P1 (E) and P3 (F).

TABLE III - Total Carotenoid (TC) content of the yellow and orange pigment extracts

\begin{tabular}{lcc}
\hline Sample & $\begin{array}{c}\text { Dry cell } \\
\text { weight }(\mathrm{g} / \mathbf{L})\end{array}$ & TC $(\boldsymbol{\mu g} / \mathbf{g})$ \\
\hline $\begin{array}{l}\text { Yellow pigment } \\
\text { extract }\end{array}$ & $2.96 \pm 0.091652$ & $318.66 \pm 34.1516$ \\
\hline $\begin{array}{l}\text { Orange pigment } \\
\text { extract }\end{array}$ & $3.1 \pm 0.182483$ & $445.33 \pm 36.0185$ \\
\hline
\end{tabular}

Each reading represents mean of three observations $\pm S D$

\section{Photostability}

Both the yellow and the orange pigments showed good photostability. A constant maximum absorbance peak was maintained up to 50 to $60 \mathrm{~min}$. The degradation is seen to begin after or around $60 \mathrm{~min}$ exposure (Figure 2). Photostability is an important property of microbial pigments that are being considered for being used as additives in topical sun protectant formulations. Good photostability would mean better prospects as the pigment would remain available to perform its other useful activities like UV protection and UV absorption and antioxidant activity for longer periods of time. 
Purified carotenoids are delicate compounds and heat, oxygen and exposure to light can result in considerable degradation (Bhosale, Jogdand, Gadre, 2003). Stability of solvent extracted pigments has been reported to last from a few hours to a few days (Kadian, Sharma, Sood, 2013). Órdenes-Aenishanslins et al. in 2016, reported greater photostability of canthaxanthin methanol extracts of Hymenobacter sp. isolated from Antartic soil as compared to zeaxanthin containing extracts from Chryseobacterium sp.

Our study analysed the stability of the pigment extracts for $60 \mathrm{~min}$ and both pigments retained near $97 \%$ stability under these evaluated conditions.
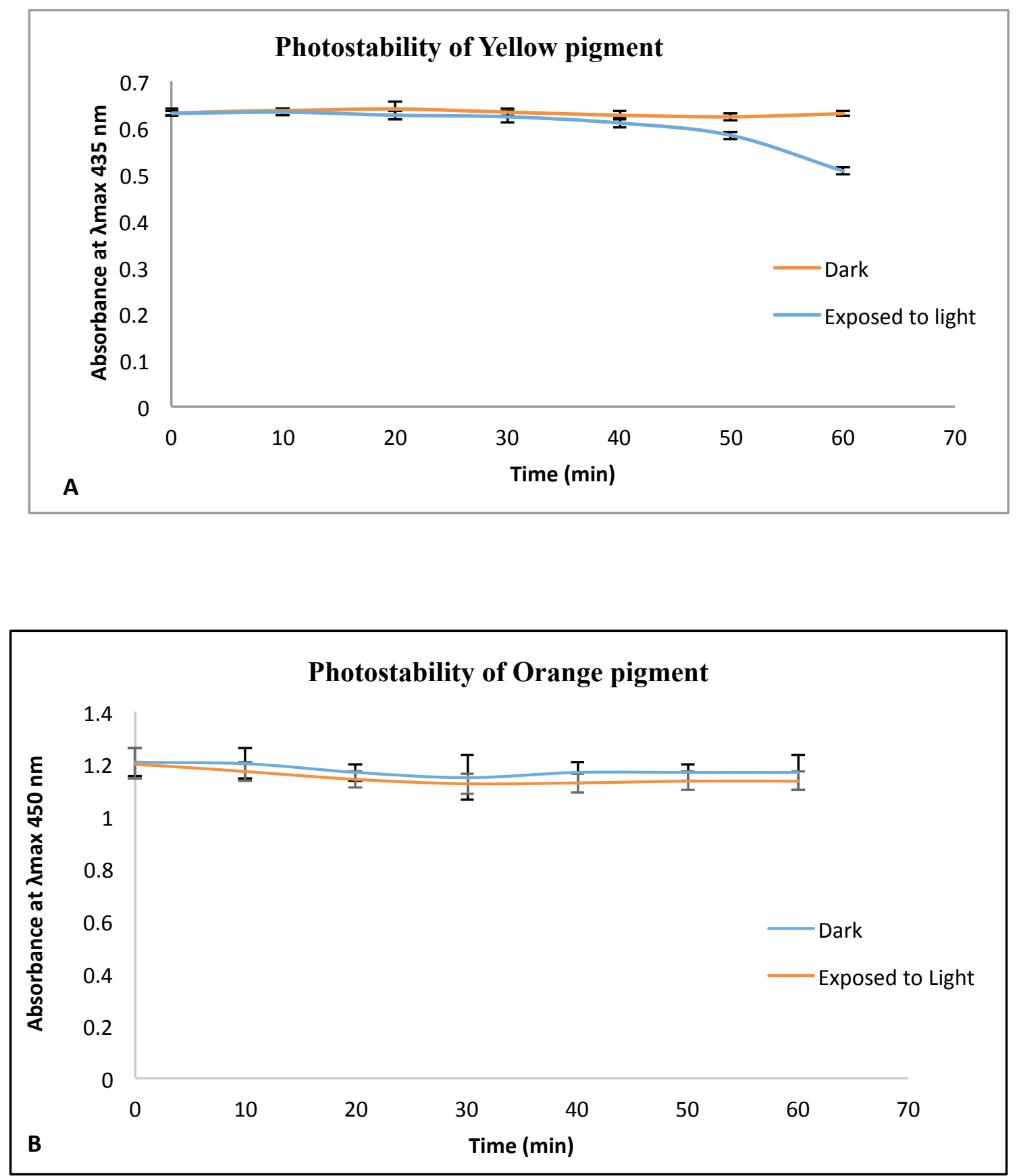

FIGURE 2 - Photostability of Yellow (A) and Orange (B) pigments determined at their respective maximum absorbance peaks (435 nm- yellow and $450 \mathrm{~nm}$-Orange). Each plotted point represents three trials expressed as mean \pm SEM. 


\section{Determination of Sun Protection Factor (SPF)}

In addition to photostability, one more important characteristic of a UV protectant compound is the ability to protect skin from damaging effects of solar radiation.

The efficacy of sunscreens is usually expressed by the Sun Protection Factor (SPF) which is defined as the ratio of the UV energy required to produce a minimal erythemal dose (MED) in protected skin and the UV energy required to produce a MED in unprotected skin. Studies on carotenoid extracted from Exiobacterium sp. revealed an SPF value of 1.785 and 2.72 (Heshmatipour, Bana, 2017). Melanin extracted from bacterial isolates grown on fruit waste extract demonstrated high SPF value of 53.73 comparable with the SPF of purchase synthetic melanin standard that showed an SPF of 59.33 (Tarangini, Mishra, 2014). The determination of SPF values was made through the UV spectrophotometric method applying the Mansur equation. The results are presented in Table IV. The orange pigment exhibited a higher SPF value of 5.31 compared to the yellow pigment that showed an SPF of 2.601. The SPF values obtained in the present study are comparable with that of other bacterial carotenoids and non-volatile oils and higher than the SPF values exhibited by aqueous herbal extracts (Chanchal, Saraf, 2010).

TABLE IV - Sun Protection Factor (SPF) of the two pigment extracts as calculated by the Mansur equation

\begin{tabular}{|c|c|c|c|}
\hline Wavelength (nm) & $\begin{array}{c}\text { Absorbance Yellow } \\
\text { pigment extract }\end{array}$ & $\begin{array}{c}\text { Absorbance Orange } \\
\text { pigment extract }\end{array}$ & $\mathbf{S P F}=\mathbf{C F} \times \sum \mathbf{E E} \times \mathbf{I} \times \mathbf{A b s}$ \\
\hline 290 & 0.63 & 0.96 & \multirow{4}{*}{$\begin{array}{c}\text { Yellow pigment extract } \\
2.601586\end{array}$} \\
\hline 295 & 0.521 & 0.931 & \\
\hline 300 & 0.38 & 0.793 & \\
\hline 305 & 0.22 & 0.494 & \\
\hline
\end{tabular}

\begin{tabular}{lccc}
\hline 310 & 0.1 & 0.191 & 0.16 \\
\hline 315 & 0.091 & 0.1 & $\begin{array}{c}\text { Orange pigment extract } \\
5.311305\end{array}$ \\
\hline$\sum$ Abs & 0.03 & 0.531131 \\
\hline
\end{tabular}

$\mathbf{E E} \times \mathbf{I}$ values obtained from TABLE I

\section{Photo-protective activity of the pigment extracts}

\section{UV protection}

P1 and P3 exhibited distinct resistance to UV radiation as compared to $E$. coli at all measured time points. Both the isolates $\mathrm{P} 1$ and $\mathrm{P} 3$ were more resistant to UVA-B radiation compared to UVC (Figure 3). The extracted pigments could similarly afford protection against both UVC and UVA-B radiation. E. coli exposed directly to radiation in the absence of pigment block, showed drastic reduction in survival within $30 \mathrm{~min}$ of exposure.

Microorganisms have evolved several strategies to cope with the environmental challenges like UV radiation. Production of UV absorbing compounds such 
as carotenoids, scytonemin and mycosporine like amino acids (MAAs) is one such strategy (Cockell, Knowland, 1999). Pigmented microorganisms have often shown better survival in the face of UV radiation exposure compared to their un-pigmented counter parts, laying proof to the notion that endogenous pigments provide an evolutionary advantage. The UV resistance of the isolates obtained in the present study was characterized by exposure to UV-C and UVA-B radiations.

Moeller et al. in 2005, reported a similar protective effect against UVA radiation on part of the red carotenoid pigments of the spores of Bacillus atrophaeus. In order to confirm that the UV resistance of the isolates is due to the pigments, the pigments were extracted and tested for their capacity to afford UV protection to UV sensitive $E$. coli strain by acting as a screen. Both the pigments caused an increase in \% $\mathrm{CV}$ of $E$. coli after radiation exposure, exhibiting photo absorptive property for UVA-B radiation. Again, very little protective effect was observed for UV-C light. Similar photo protection of fibroblasts and human skin from UVA damage was reported for bacteria derived melanin pigment (Geng et al., 2008). Hama et $a l$. in 2012, reported prevention of UV induced skin damage by topical application of astaxanthin liposome formulation. The present study indicates that the extracted pigments can produce photoprotective effect even when used topically.

\section{Antibacterial activity of pigment extracts}

The appearance of zone of inhibition (ZOI) (Table V) confirmed the antibacterial property exhibited by both the pigment extracts. Yellow pigment extract (zeaxanthin) demonstrated stronger inhibition of test organisms in comparison to the orange pigment extract (beta carotene and canthaxanthin).

Bacterial pigments have been long known to exhibit antimicrobial properties. Pigments such as carotenoids, melanins, flavins, quinones, monascins, violacein, and indigo have been reported as good antimicrobial agents (Malik, Tokkas, Goyal, 2012).

The order of antibacterial activity was found to be Penicillin standard $>$ Yellow pigment extract $>$ Orange pigment extract.

It has been pointed out previously that the chemistry of the pigments has significant effect on the potency of antimicrobial effect (Manimala, Murugesan, 2014). Xanthaphylls of microbial origin like Astaxanthin and Sarcinaxanthin have been reported to have good antimicrobial activity (Irna et al., 2017; Umadevi, Krishnaveni, 2013). The yellow pigment extracted in the present study was identified as a xanthophyll (Zeaxanthin or astaxanthin). Its antibacterial properties closely align with those of xanthophyll's. The susceptibility was not related to the gram stain nature of the test organisms in the present study. In a study on the antimicrobial activity of topical skin pharmaceuticals Alsterholm et al. in 2010, pointed out that in limited skin infections, topical antimicrobials can be a better alternative to systemic antibiotics. This study also expressed strong need for new topical non-resistance promoting antimicrobial preparations for the treatment of skin infections. Antibacterial activity of red pigment extracted from Vibrio sp. when applied topically on inflicted wounds in Wistar rats was reported by Krishna et al. in 2017. Considering the possibility of pigments being used as supplements in topical applications, their antimicrobial activity would prove to be a definite advantage over other cosmetic and pharmaceutical products.

\section{Antioxidant activity of pigment extracts}

Both the pigment extracts exhibited antioxidant activity as is evident from the \% of scavenging activity readings presented in Figure 4. At a maximum concentration $500 \mu \mathrm{g} / \mathrm{mL}$ the orange pigment extract showed $52.36 \%$ scavenging while the yellow pigment extract showed $36.69 \%$. The order of antioxidant activity was ascorbic acid $>$ orange pigment $>$ yellow pigment. The antioxidant activity increased with increasing concentration of pigment extracts.

Microbial pigments are known to be the strongest natural antioxidants. Because of their antioxidant function and blue light filtering carotenoids are quite plausible as components to be used in sunscreens (Morabito et al., 2011).

In this section, we tested the pigment extracts for their antioxidant potential through DPPH assay. Both the yellow and orange pigment extracts exhibited antioxidant activity by reducing stable free radical DPPH to the yellow 1,1-diphenyl-2-picrylhydrazyl. Reduction in absorbance at $517 \mathrm{~nm}$ is indicative of antioxidant potential. The $\%$ inhibition of DPPH showed an increase over a range of $10-35 \%$ for the yellow pigment and $12-48 \%$ for the orange pigment with increasing concentrations with maximum tested concentration being $500 \mu \mathrm{g} / \mathrm{mL}$. The activity was significantly weaker as compared to 

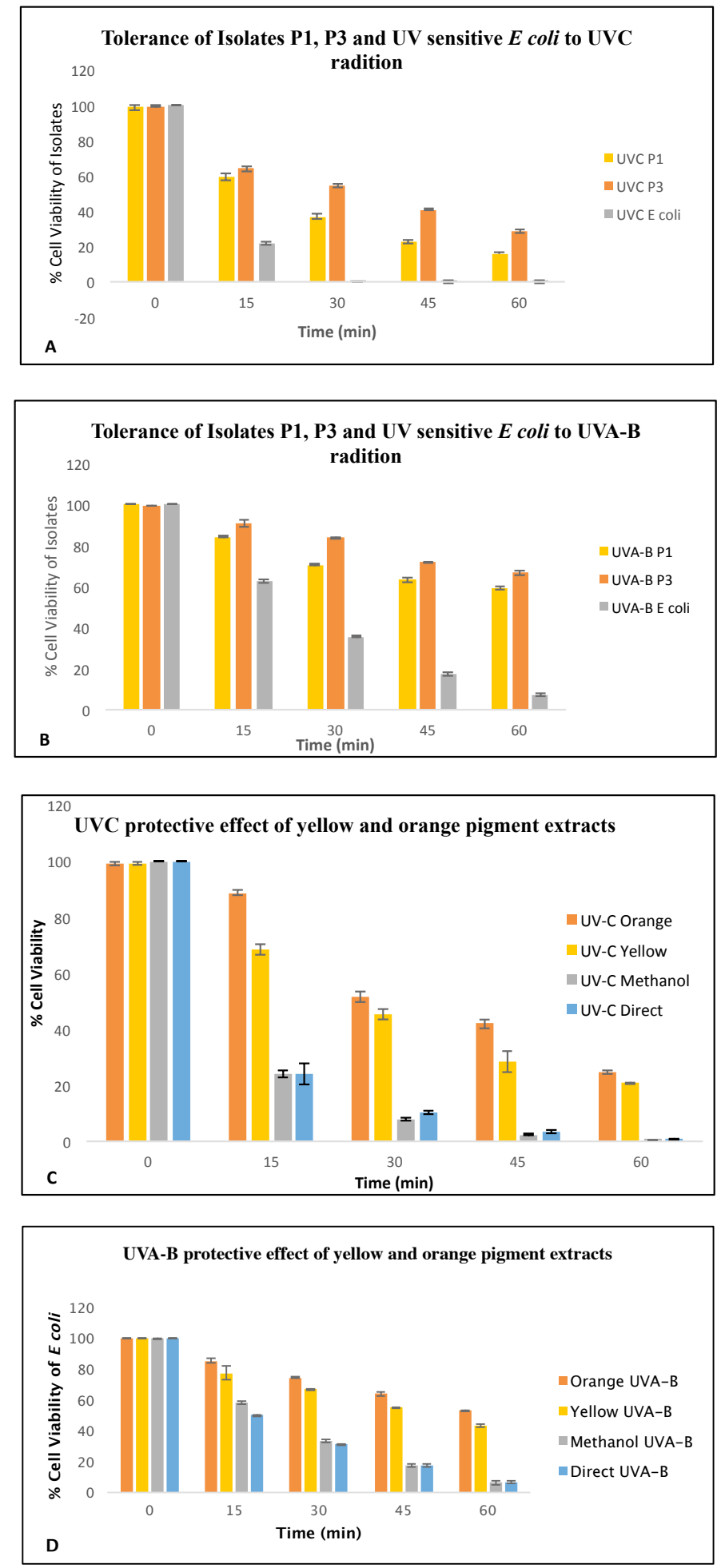

FIGURE 3 - Tolerance of the isolates $\mathrm{P}(1)$ and $\mathrm{P}(3)$ to UV radiation; UV-C radiation (A) and UVA-B radiation (B). UV protective effect of the methanolic pigment extracts; UV-C radiation (C) and UVA-B radiation (D). Each bar represents three trials expressed as mean $\pm \mathrm{SEM}$. 
TABLE V - Antibacterial activity of methanolic extracts $(0.5-5 \mathrm{mg} / \mathrm{mL})$ of pigments. Diameter of zone of inhibition (ZOI) of bacterial growth (mm)

\section{Yellow pigment (P1)}

\section{Zone of Inhibition (mm)}

Test organism/Concentration

$\begin{array}{llllll}0.5 \mathrm{mg} / \mathrm{mL} & 1.5 \mathrm{mg} / \mathrm{mL} \quad 2.5 \mathrm{mg} / \mathrm{mL} \quad 3.5 \mathrm{mg} / \mathrm{mL} \quad 5 \mathrm{mg} / \mathrm{mL} \quad \text { Penicillin }\end{array}$

\begin{tabular}{lccccc}
\hline Escherichia coli & $4.6 \pm 0.16$ & $5.3 \pm 0.33$ & $5.5 \pm 0.28$ & $7 \pm 0.28$ & $15.8 \pm 0.16$ \\
\hline Staphylococcus aureus & $5.6 \pm 0.33$ & $6.3 \pm 0.33$ & $7.3 \pm 0.33$ & $7.7 \pm 0.33$ & $16 \pm 0.57$ \\
\hline Klebsiella pneumonae & $4.6 \pm 0.33$ & $5.6 \pm 0.33$ & $6 \pm 0.28$ & $6.3 \pm 0.33$ & $11 \pm 0.57$ \\
\hline Bacillus subtilis & 0 & 0 & $0.5 \pm 0.28$ & $1.5 \pm 0.28$ & $1.6 \pm 0.33$ \\
\hline Corynebacterium diptheriae & $4.6 \pm 0.33$ & $5.8 \pm 0.16$ & $6.5 \pm 0.28$ & $7.2 \pm 0.60$ & $15 \pm 0.57$ \\
\hline Pseudomonas aeruginosa & $3.3 \pm 0.16$ & $5.2 \pm 0.16$ & $5.5 \pm 0.50$ & $7 \pm 0$ & $10.2 \pm 0.44$ \\
\hline Sarcina lutea & $3.3 \pm 0.16$ & $4.2 \pm 0.16$ & $5.3 \pm 0.44$ & $6.8 \pm 0.44$ & $10.6 \pm 0.44$ \\
\hline
\end{tabular}

\section{Orange pigment (P3)}

\section{Zone of Inhibition (mm)}

Test organism/Concentration

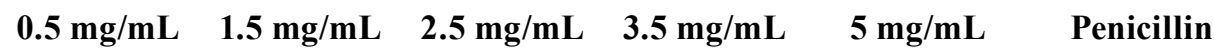

\begin{tabular}{lcccccc}
\hline Escherichia coli & 0 & 0 & $0.5 \pm 0.28$ & $0.8 \pm 0.41$ & $1.3 \pm 0.16$ & 12 \\
\hline Staphylococcus aureus & 0 & 0 & $0.5 \pm 0.28$ & $0.7 \pm 0.33$ & $1.1 \pm 0.57$ & $2 \pm 0.50$ \\
\hline Klebsiella pneumonae & 0 & 0 & $0.4 \pm 0.28$ & $0.5 \pm 0.28$ & $1.6 \pm 0.28$ & 14 \\
\hline Bacillus subtilis & 0 & 0 & $0.7 \pm 0.28$ & $0.8 \pm 0.33$ & $1.5 \pm 0.26$ \\
\hline Corynebacterium diptheriae & $0.3 \pm 0.33$ & $0.7 \pm 0.35$ & $1.2 \pm 0.12$ & $1.3 \pm 0.11$ & 20 \\
\hline Pseudomonas aeruginosa & 0 & $0.8 \pm 0.14$ & $1.2 \pm 0.17$ & $2.2 \pm 0.31$ & $2.4 \pm 0.44$ \\
\hline Sarcina lutea & $0.6 \pm 0.33$ & $1.1 \pm 0.24$ & $1.4 \pm 0.23$ & $2.2 \pm 0.14$ & $6.7 \pm 0.43$ \\
\hline
\end{tabular}

Each reading represents mean of three observations $\pm \mathrm{SD}$ 
that of the standard ascorbic acid $(96.7 \%$ inhibition at $500 \mu \mathrm{g} / \mathrm{mL}$ ) (Figure 4)

Irna et al. in 2017, reported antioxidant activity of astaxanthin extracted from the carapace of shrimp Paeneus monodon. It was observed that the pigment extracted with high pressure processing (HPP) extraction showed better performance as an antioxidant $(87.90 \%$ inhibition) as compared to the chemically extracted astaxanthin fraction (25.47\% inhibition).

Rostami et al. in 2016, showed antioxidant activity of carotenoids extracted from Micrococcus roseus and Rhodotorula glutinis. They attributed the higher antioxidant activity of $M$. roseus extracts to its higher beta carotene content as beta carotene is known to have very high antioxidant activity.

Thus, antioxidant activity observed in in vitro assays depends upon the purity of the extract, the total carotenoid content as well as the type or the composition of the carotenoid present.

Other factors may be the solvent used for extraction and the method of analysis of antioxidant activity. Preparation of complexes of pigments extracted from natural sources with other compounds can increase stability while retaining satisfactory anti-oxidant activity facilitating topical use.

Topical application of pordigiosin and violecin along with plant extracts not only increased the SPF but also showed antioxidant activity $30 \%$ and $20 \%$ respectively of that of standard ascorbic acid (Suryawanshi, et al., 2014).
Darvin et al. in 2011 showed that topical application of beta carotene $(2 \mathrm{mg} / \mathrm{cm} 2)$ provided protection for human skin when exposed to infrared radiation. Carotenoids have always been known as dietary sunscreens. However, whether the effect can be seen when applied topically on the skin is the real challenge.

\section{CONCLUSIONS}

This study analysed the potential of two microbe derived pigments with respect to their use as topical photo-protectants for humans. The pigments were characterized as carotenoids, one of them being a xanthophyll and the other predominantly a carotene. Both pigments showed good ultraviolet radiation protective ability. The pigments were found to be photostable with moderately good SPF values. In addition, the pigments were also found to exhibit antioxidant and antimicrobial properties.. All in all the microbial pigments tested in this study demonstrate promising potential towards development of natural UV protective/sunscreen compounds. This study, to the best of our knowledge, is one of the very few reports that direct attention towards testing bacterial pigments for possible photoprotective potential. The study also highlights the importance of the property of photostability of the pigments with respect to their use as topical applicants. More studies can be directed towards improving the photostability of bacterial pigments.

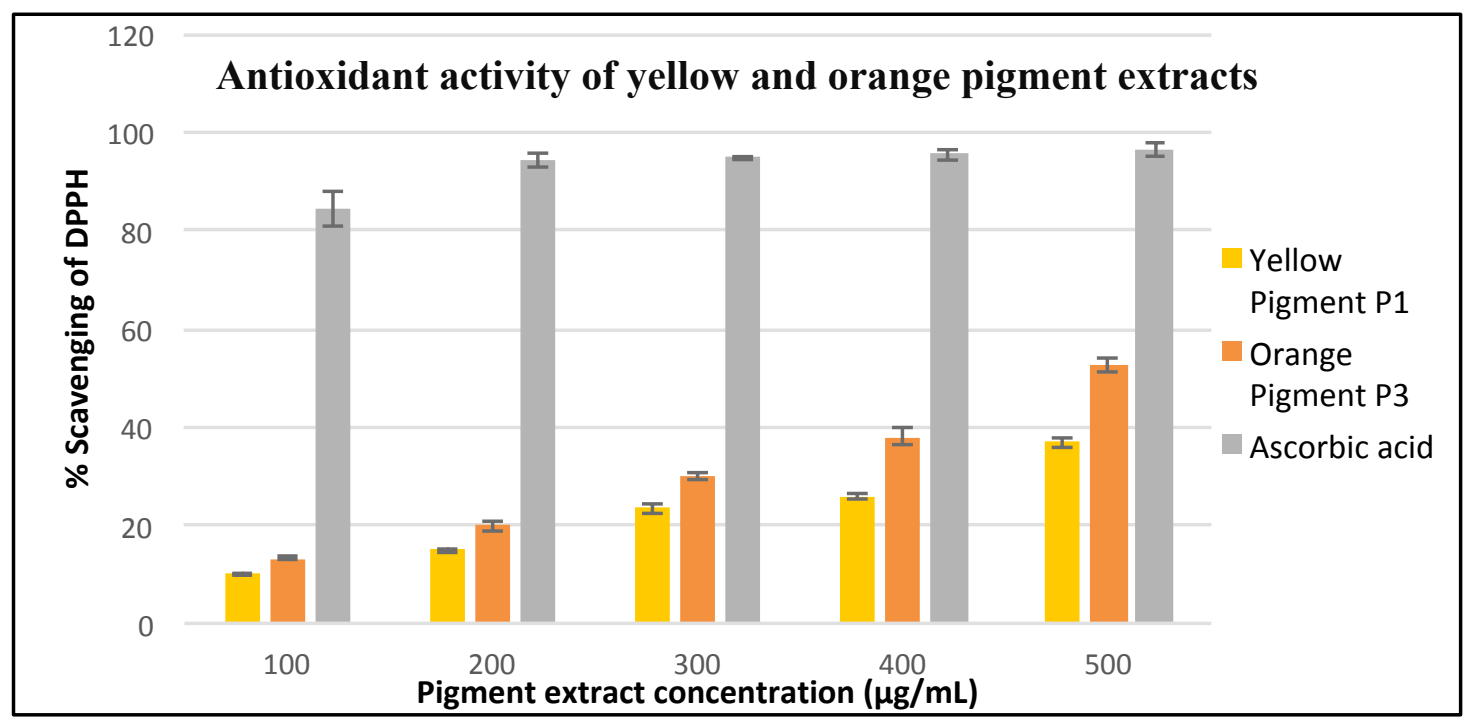

FIGURE 4 - Antioxidant activity of methanolic extracts $(100-500 \mu \mathrm{g} / \mathrm{mL})$ of pigments. \% scavenging of DPPH. Each bar represents three trials expressed as mean \pm SEM. 


\section{ACKNOWLEDGEMENTS}

The authors thank the School of Biotechnology and Bioinformatics, D Y Patil Deemed to be University, Navi Mumbai for extending laboratory facilities and providing part funding for this work.

\section{AUTHOR CONTRIBUTIONS}

Jyoti Patki: Conceived and designed this study, analyzed the data, contributed new methods and models and wrote this article.

Suvidha Singh: Performed this research and contributed new methods and models.

Sunita Singh: Contributed to study design, analyzed the data, contributed new methods and models and critically reviewed the article.

Naveen Padmadas: Analyzed the data and critically reviewed the article.

Debjani Dasgupta: Contributed new methods and models and critically reviewed the article.

\section{CONFLICT OF INTEREST}

The authors declare that they have no conflict of interest in the publication.

\section{DATA AVAILABILITY}

All data generated or analyzed in this study are included in this published article.

\section{REFERENCES}

Ajayi IA, Ajibade O, Oderinde RA. Preliminary phytochemical analysis of some plant seeds. Res J Chem Sci. 2011;1(3):58-62.

Alsterholm M, Karami N, Faergemann J. Antimicrobial activity of topical skin pharmaceuticals - an in vitro study. Acta Derm Venereol. 2010;90(3):239-45 doi: 10.2340/00015555-0840.

Anand S. Indian cosmetic industry: A short perspective document on the cosmetics retail sector. 2017; July. Available from: http://redseer.com/wp-content/uploads/2017/10/118Cosmetics-Industry-Report_Final_July2017.pdf

Bhosale P, Jogdand VV, Gadre RV. Stability of b-carotene in spray dried preparation of Rhodotorula glutinis mutant 32 . J Appl Microbiol. 2003;95(3):584-590. doi:10.1046/j.13652672.2003.02018.x
Chanchal Deep Kaur, Saraf S. In vitro sun protection factor determination of herbal oils used in cosmetics. Pharmacognosy Res. 2010;2(1):22-25. doi: 10.4103/09748490.60586 .

Chávez-Parga MDC, Munguía-Franco A, Aguilar-Torres M, Escamilla-Silva EM. Optimization of Zeaxanthin production by immobilized Flavobacterium sp. Cells in fluidized bed bioreactor. Adv Microbiol. 2012;2(4):598-604 doi:10.4236/ aim.2012.24078

Cockell CS, Knowland J. Ultraviolet radiation screening compounds. Biol Rev Camb Philos Soc. 1999;74(3):311-45.

Darvin ME, Fluhr JW, Meinke MC, Zastrow L, Sterry W, Lademann J. Topical beta-carotene protects against infra-redlight-induced free radicals. Exp Dermatol. 2011;20(2):125129. doi: 10.1111/j.1600-0625.2010.01191.x.

Mohana DC, Thippeswamy S, Abhishek RU. Antioxidant, antibacterial, and ultraviolet-protective properties of carotenoids isolated from Micrococcus spp. Radiat Prot Environ. 2013;36(4):168-74.

Dufosse'L, Mabon P, Binet A. Assessment of the coloring strength of Brevibacterium linens strains: spectrocolorimetry versus total carotenoid extraction/quantification. J Dairy Sci. 2001;84(2):354-360.

Dutra EA, Oliveira DAGC, Kedor-Hackman ERM, Santoro MIRM. Determination of sun protection factor (SPF) of sunscreens by ultraviolet spectrophotometry. Braz J Pharm Sci. 2004;4(3):381-385.

Gavrish EY, Krauzova VI, Potekhina NV, Karasev SG, Plotnikova EG, Altyntseva OV, Korosteleva LA, Evtushenko LI. Three New Species of Brevibacteria, Brevibacterium antiquum sp. nov., Brevibacterium aurantiacum sp. nov., and Brevibacterium permense sp. nov. Microbiology 2004;73(2):176-183.

Geng J, Tang W, Wan X, Zhou Q, Wang XJ, Shen P, Lei, TC, Chen XD. Photoprotection of bacterial-derived melanin against ultraviolet A-induced cell death and its potential application as an active sunscreen. J Eur Acad Dermatol Venereol. 2008;22(7):852-858 doi: 10.1111/j.14683083.2007.02574.x. Epub 2008 Feb 27

Hama S, Takahashi K, Inai Y, Shiota K, Sakamoto R, Yamada A, Tsuchiya H, Kanamura K, Yamashita E, Kogure K. Protective effects of topical application of a poorly soluble antioxidant astaxanthin liposomal formulation on ultravioletinduced skin damage. J Pharm Sci. 2012;101(8):2909-2916 doi: 10.1002/jps.23216. Epub 2012 May 24 
Heshmatipour Z, Bana M. Isolation of pigment-producing bacteria from surface water and study of Sun Protection Factor (SPF) of purified pigments. Int J Adv Sci Eng Technol. 2017;5(1)(Suppl 1):103-108.

Holt JG, Krieg NR, Sneath PHA, Staley JT, Williams ST Bergey's Manual of Determinative Bacteriology $9^{\text {th }}$ Edition (1994) Lippincott Williams and Wilkins; Editor: William R Hensyl Philadelphia USA

Ishihashi M, Ueda M, Budiyanto A, Bito T, Oka M, Fukunaga M, Tsuru K, Horikawa T. UV induced skin damage. Toxicology. 2003;189(1-2):21-39.

Irna C, Jaswir I, Othman R, Jimat DN. Antioxidant and antimicrobial activities of astaxanthin from Penaeus monodon in comparison between chemical extraction and High-Pressure Processing (HPP) Int Food Res J. 2017;24(Suppl):508-513.

Jalal KCA, Azira ZZA, Zakaria NH, Rahman MMZ, Kamaruzzaman Y, Faizul, N. Carotenoid contents in anoxygenic phototrophic purple bacteria, Marichromatium sp. and Rhodopseudomonas sp. of tropical aquatic environment, Malaysia. Oriental J Chem. 2014;30(2):607-613.

Joshi VK, Attri D, Bala A, Bhushan S. Microbial pigments. Ind J Biotechnol. 2003;2:362-369.

Kadian SS, Sharma A, Sood DR. Effect of light and heat on stability of crude Carotenoid extract from Natural sources. Int J Pharm Sci Res. 2013;4(6):2415-2418 doi: 10.13040/ IJPSR.0975-8232.4(6).2415-18

Krishna PS, Sudha S, Reddy KA, Al-Dhabaan FA, Meher, Prakasham RS, Charya MAS. Studies on wound healing potential of red pigment isolated from marine bacterium Vibrio sp. Saudi J Biol Sci. 2019;26(4):723-729. https:// doi.org/10.1016/j.sjbs.2017.11.035 https://doi.org/10. 1016/j. sjbs.2017.11.035

Malik K, Tokkas J, Goyal S. Microbial pigments: a review. Int J Microb Res Technol. 2102;1361-1365.

Manimala MRA, Murugesan R. In vitro antioxidant and antimicrobial activity of carotenoid pigment extracted from Sporobolomyces sp. isolated from natural source. J Appl Nat Sci. 2014;6(2):649-653.

Mansur JS, Breder MNR, Mansur MCA, Azulay RD. Determination of Sun Protection Factor by Spectrophotometry. An Bras Dermatol. 1986; 61:121-124.

Moeller R, Horneck G, Facius R, Stackebrandt E. Role of pigmentation in protecting Bacillus sp. Endospores against environmental UV radiation FEMS Microbiol Ecol 2005;51(2):231-236.

Mohammadi M, Burbank L, Roper MC. Biological Role of Pigment Production for the Bacterial Phytopathogen Pantoea stewartii subsp. Stewartii. App Environm Microbiol. 2012;78(19):6859-6865 doi:10.1128/AEM.01574-12.

Morabito K, Shapley NC, Steeley KG, Tripathi A. Review of sunscreen and the emergence of non-conventional absorbers and their applications in ultraviolet protection Int J Cosmetic Sci. 2011;33(5):385-390. doi: 10.1111/j.14682494.2011.00654.x

Narsing Rao MP, Xiao M, Li WJ. Fungal and bacterial pigments: secondary metabolites with wide applications. Front Microbiol. 2017;8:1113 doi: 10.3389/fmicb.2017.01113

Órdenes-Aenishanslins N, Anziani-Ostuni G, Vargas-Reyes M, Alarcón J, Tello A, Pérez-Donoso JM. Pigments from UV-resistant antarctic bacteria as photosensitizers in dye sensitized solar cells. J Photochem Photobiol, B: Biology. 2016;162:707-714.

Rameshkumar N, Nair S. Isolation and molecular characterization of genetically diverse antagonistic, diazotrophic red-pigmented vibrios from different mangrove rhizospheres. FEMS Microbiol Ecol. 2009;67(3):455-467. https://doi.org/10.1111/j.1574-6941.2008.00638.x

Rivera S, Canela R. Influence of sample processing on the analysis of carotenoids in maize. Molecules. 2012;17(9):1125511268. doi:10.3390/molecules170911255

Rostami H, Hamedi H, Yolmeh M. Some biological activities of pigments extracted from Micrococcus roseus (PTCC 1411) and Rhodotorula glutinis (PTCC 5257). Int J Immunopathol Pharmacol. 2016;29(4):684-695.

Samyukta S, Mahajan SN. Isolation and Identification of pigment producing bacteria and characterization of the extracted pigments. Int J Appl Res. 2016;2(7):657-664.

Saseeswari A, Kanimozhi G, Panneerselvam A. Bacterial Diversity of Mangrove Soil in Karankadu from East Coast of Tamil Nadu, India. Int J Curr Microbiol App.Sci. 2016;5(4):750-756.

Sayre RM, Agin PP, Levee GJ, Marlowe E. Comparison of in vivo and in vitro testing of sunscreening formulas. Photochem Photobiol. Oxford 1979;29(3):559-566.

Siezen RJ. Genomic updates: Microbial Sunscreens. Microb Biotechnol. 2011;4(1):1-7. 
Suryawanshi RK, Patil CD, Borase HP, Narkhede CP, Stevenson A, Hallsworth JE, Patil SV. Towards an understanding of bacterial metabolites prodigiosin and violacein and their potential for use in commercial sunscreens. Int J Cosmetic Sci. 2014;37(1):98-107. https://doi. org/10.1111/ics.12175

Tarangini K, Mishra S. Production of melanin by soil microbial isolate on fruit waste extract: two step optimization of key parameters. Biotechnol Rep. 2014;4:139-146. http:// dx.doi.org/10.1016/j.btre.2014.10.001

Umadevi K, Krishnaveni M. Antibacterial activity of pigment produced from Micrococcus luteus KF532949. Int J Chem Analyt Sci. 2013;4(3):149-152.
Venil CK, Zakaria ZA, Usha R, Ahmad WA. Isolation and characterization of flexirubin type pigment from Chryseobacterium sp. UTM-3T. Biocatalysis and Agricultural Biotechnology. 2014;3(4):103-107. http://dx.doi.org/10.1016/j. bcab.2014.02.006

Wu P, Xiong X, Xu Z, Lu C, Cheng H, Lyu X, et al. Bacterial Communities in the Rhizospheres of Three Mangrove Tree Species from Beilun Estuary, China. PLoS ONE. 2016;11(10): e0164082 https://doi.org/10.1371/journal.pone.0164082

Received for publication on $23^{\text {rd }}$ March 2019 Accepted for publication on $29^{\text {th }}$ September 2019 